\title{
Comparative efficacies of different antibiotic treatments to eradicate nontypeable Haemophilus influenzae infection
} Yukie Sekiya ${ }^{1}$, Masahiro Eguchi ${ }^{1,2}$, Masahiko Nakamura ${ }^{3}$, Kimiko Ubukata ${ }^{1,2}$, Satoshi Omura ${ }^{1,2}$ and Hidenori Matsui ${ }^{* 1,2}$

Address: ${ }^{1}$ Center for Basic Research, The Kitasato Institute, 5-9-1 Shirokane, Minato-ku, Tokyo 108-8642, Japan, ${ }^{2}$ Kitasato Institute for Life Sciences and Graduate School of Infection Control Sciences, 5-9-1 Shirokane, Minato-ku, Tokyo 108-8641, Japan and ${ }^{3}$ Center for Clinical Pharmacy and Clinical Sciences, School of Pharmaceutical Sciences, 5-9-1 Shirokane, Minato-ku, Tokyo 108-8641, Japan

Email: Yukie Sekiya - ysekiya@lisci.kitasato-u.ac.jp; Masahiro Eguchi - meguchi@lisci.kitasato-u.ac.jp;

Masahiko Nakamura - nakamura@pharm.kitasato-u.ac.jp; Kimiko Ubukata - ubukata@lisci.kitasato-u.ac.jp; Satoshi Omura - omura@kitasatou.ac.jp; Hidenori Matsui* - hmatsui@lisci.kitasato-u.ac.jp

* Corresponding author

Published: 7 February 2008

BMC Infectious Diseases 2008, 8:15 doi:10.1/86/147I-2334-8-15
Received: 27 August 2007

Accepted: 7 February 2008

This article is available from: http://www.biomedcentral.com/147I-2334/8/15

(C) 2008 Sekiya et al; licensee BioMed Central Ltd.

This is an Open Access article distributed under the terms of the Creative Commons Attribution License (http://creativecommons.org/licenses/by/2.0), which permits unrestricted use, distribution, and reproduction in any medium, provided the original work is properly cited.

\begin{abstract}
Background: Nonencapsulated and nontypeable Haemophilus influenzae (NTHi) is a major cause of human respiratory tract infections. Some strains of NTHi can cause invasive diseases such as septicemia and meningitis, even if $H$. influenzae is not generally considered to be an intracellular pathogen. There have been very few reports about the therapeutic efficacy of antibiotics against respiratory tract infection caused by NTHi in mice because it is difficult for $\mathrm{H}$. influenzae to infect mice. Therefore, we evaluated the efficacy of antibiotics against NTHi in both a cell culture model and a mouse model of infection.

Methods: We used six strains of NTHi isolated from adult patients with chronic otitis media, namely three $\beta$-lactamase-negative ampicillin (AMP)-resistant (BLNAR) strains and three $\beta$-lactamase-negative AMP-susceptible (BLNAS) strains, to evaluate the efficacy of AMP, cefcapene (CFPN), levofloxacin (LVX), clarithromycin (CLR), and azithromycin (AZM) in both a cell culture infection model and a mouse infection model. In the cell culture infection model, strains that invade A549 human alveolar epithelial cells were treated with each antibiotic $(\mathrm{l} \mu \mathrm{g} / \mathrm{ml})$. In the mouse infection model, female $\mathrm{C} 57 \mathrm{BL} / 6$ mice were intraperitoneally injected with cyclophosphamide $(200 \mathrm{mg} / \mathrm{kg})$ three days before intranasal infection with $\mathrm{I} \times 10^{9}$ colony-forming units (CFU) of NTHi and on the day of infection. After infection, the mice were orally administered each antibiotic three times daily for three days, except for AZM, which was administered once daily for three days, at a dose of $100 \mathrm{mg} / \mathrm{kg} / \mathrm{day}$.

Results: In the cell culture infection model, it was found that two BLNAR strains were able to enter the cell monolayers by the process of macropinocytosis, and treatment with LVX yielded good bactericidal activity against both strains inside the cells. In the mouse infection model, no bacteria were detected by means of plating the lung homogenates of LVX-treated mice at day 4 after infection, while more than $10^{5}$ CFU of bacteria per tissue sample were detected in nontreated mice.

Conclusion: Our findings show the outcome and rich benefits of fluoroquinolone treatment of respiratory infections caused by either invasive or noninvasive BLNAR strains of NTHi.
\end{abstract}




\section{Background}

Haemophilus influenzae, a species that can cause systemic disease in humans, is an obligate human commensal found principally in the upper respiratory tract [1]. $H$. influenzae can express one or none of six antigenically distinct polysaccharide capsules [1]. H. influenzae type b (Hib) penetrates the nasopharyngeal mucosa of its host by a presently unknown mechanism [2]. An in vitro invasion assay showed that Hib has a very weak propensity to enter cultured epithelial cells [2]. In contrast, a decapsulated mutant of Hib was found to be consistently 20 to 100 times more invasive than its wild type [2]. Moreover, nonencapsulated and nontypeable $H$. influenzae (NTHi) are consistently over 1,000 times more invasive than Hib [2]. Some strains of NTHi can cause invasive diseases such as septicemia and meningitis, which suggests that the bacteria can pass through the cell layers and survive within both epithelial and endothelial cells [3]. Actually, it has been reported that NTHi can pass through viable cell layers of the human lung epithelial cell line NCI-H292 by paracytosis, thus requiring bacterial protein synthesis, even though the passage time is dependent on the growth rate, which is influenced by the bacterial strains [4]. Although NTHi is a major cause of human infections at present, to the best of our knowledge only one comparative evaluation of antibiotics using an NTHi infection model in mice has been reported [5]. As a matter of fact, mouse models of infection are not typical for $H$. influenzae because it is difficult for this bacterium to infect mice via the respiratory route.

In the present study, we utilized the A549 human lung epithelial cell line to characterize the invasive phenomena of six clinically isolated strains of NTHi, namely three $\beta$ lactamase-negative ampicillin (AMP)-resistant (BLNAR) strains and three $\beta$-lactamase-negative AMP-susceptible (BLNAS) strains. Two invasive strains were identified among these six strains, and the invasive strains were then used to evaluate the efficacy of antibiotics including AMP, cefcapene (CFPN), levofloxacin (LVX), clarithromycin (CLR), and azithromycin (AZM) in a cell culture model of infection. In addition, the efficacy of each antibiotic was also evaluated against each of the six isolated strains in an established mouse model of chronic pulmonary infection with the required chemically induced damage before infection.

We show that LVX was the most effective antibiotic against each NTHi strain across both cell culture and mouse infection models.

\section{Methods \\ Study design}

This study was approved by the Ethics Committee on Investigations of Experimental Pain in Conscious Ani- mals, Kitasato Institute for Life Sciences, Kitasato University, which followed internationally recognized guidelines.

\section{Bacterial strains and culture conditions}

We used six NTHi strains isolated in 2005 from adult patients with otitis media in Japan (age range, 24-68 years; mean age, 40.5 years): three strains of BLNAR (YS001, YS002, and YS005) for which the AMP minimum inhibitory concentration (MIC) was $\geq 1.0 \mu \mathrm{g} / \mathrm{ml}$, and three strains of BLNAS (YS008, YS009, and YS010). Bacteria were grown without shaking in brain heart infusion (BHI) broth (Becton Dickinson and Company, Sparks, MD, USA) supplemented with $\beta$-nicotinamide adenine dinucleotide $(\beta$-NAD; $15 \mu \mathrm{g} / \mathrm{ml})$ and hemin $(15 \mu \mathrm{g} / \mathrm{ml})$ in $5 \% \mathrm{CO}_{2}$ for $18 \mathrm{~h}$ at $37^{\circ} \mathrm{C}$. A portion of this culture was inoculated into fresh $\mathrm{BHI}$ broth supplemented with $\beta$ NAD and hemin at a concentration of $10 \%$ (vol/vol). The fresh culture was then incubated without shaking in 5\% $\mathrm{CO}_{2}$ for $3 \mathrm{~h}$ at $37^{\circ} \mathrm{C}$ before infection.

\section{MIC}

A routine agar dilution method was used to determine the MIC of the antibiotics [6]. The test strains were inoculated onto Muller-Hinton agar (Becton Dickinson and Company) supplemented with $0.5 \%$ yeast extract, $2 \%$ horse lysate instead of $\beta$-NAD and hemin in $5 \% \mathrm{CO}_{2}$ for $18 \mathrm{~h}$ at $37^{\circ} \mathrm{C}$.

\section{Cell culture model for $\mathrm{H}$. influenzae infection}

A549 cells (human lung carcinoma epithelial cell line, American Type Culture Collection CCL-185; Manassas) were cultured in Dulbecco's modified Eagle's medium (DMEM; Sigma-Aldrich, St. Louis, MO, USA) containing $10 \%(\mathrm{vol} / \mathrm{vol})$ heat-inactivated fetal calf serum, penicillin $(100 \mathrm{U} / \mathrm{ml})$, and streptomycin $(100 \mu \mathrm{g} / \mathrm{ml})$. Cell cultures were seeded at a density of $1 \times 10^{5}$ cells per well in 24 -well tissue culture plates with antibiotic-free culture medium $18 \mathrm{~h}$ prior to bacterial infection. The cell monolayers were rinsed three times with Hanks' balanced salt solution (HBSS; Sigma-Aldrich) to remove the antibiotics completely before bacterial infection.

For the invasion suppression assay of antibiotics, A549 cells were infected with NTHi at a multiplicity of infection (MOI) of 100 bacteria per host cell in the presence or absence (control) of $1 \mu \mathrm{g} / \mathrm{ml}$ of the antibiotic being tested (AMP, AZM, CLR, CFPN, and LVX). A mild centrifugal force $(600 \times \mathrm{g}$ for $5 \mathrm{~min})$ was applied to the 24-well tissue culture plates at the start of the infection period. After infection in $5 \% \mathrm{CO}_{2}$ for $1 \mathrm{~h}$ at $37^{\circ} \mathrm{C}$, the infected monolayers were gently washed three times with $1 \mathrm{ml}$ HBSS to remove noninvasive bacteria, and incubated for $1 \mathrm{~h}$ in fresh medium containing gentamicin (GEN; $100 \mu \mathrm{g} / \mathrm{ml}$ ) to kill the extracellular bacteria [2,7-9]. After incubation 
for $1 \mathrm{~h}$, the monolayers were washed three times with HBSS and lysed by vigorous aspiration with $1 \mathrm{ml}$ phosphate buffered saline (PBS; pH 7.4) containing 0.1\% (wt/ vol) sodium deoxycholate. The intracellular bacterial colony-forming units (CFU) were enumerated by diluting the lysed cells with PBS containing $0.01 \%$ (wt/vol) gelatin (BSG) [10] and plating them on the BHI agar (Becton Dickinson) supplemented with $\beta$-NAD and hemin using triplicate sampling of each infected well.

For the intracellular killing assay of antibiotics, after a 1-h treatment of GEN followed by a 1-h infection in the absence of antibiotics, the monolayers were washed three times with HBSS and were then further incubated with fresh culture medium in the presence or absence (control) of the antibiotic being tested in $5 \% \mathrm{CO}_{2}$ for $2 \mathrm{~h}$ at $37^{\circ} \mathrm{C}$. After an additional $2 \mathrm{~h}$ of incubation, the monolayers were washed three times with HBSS, and the intracellular bacteria were harvested to enable enumeration of the bacterial CFU, as described above.

\section{TEM}

Infected cell monolayers on tissue culture inserts were fixed with a fixative composed of $1 \%$ glutaraldehyde and $4 \%$ formaldehyde in a $0.06 \mathrm{M}$ phosphate buffer ( $\mathrm{pH} 7.4$ ). Samples were dehydrated in graded ethanol solutions, and embedded in Epon 812 mixture (Ladd Research Industries; Williston, VT, USA). Ultrathin sections were made with a LKB ultramicrotome (Pharmacia LKB, Uppsala, Sweden), stained with aqueous uranyl acetate and lead citrate, and analyzed with a JEOL 1200 EX-II transmission electron microscope (TEM; JEOL Ltd., Tokyo, Japan) at $80 \mathrm{kV}$ as an accelerating voltage.

\section{Mouse model for $\mathbf{H}$. influenzae infection}

Four-week-old female C57BL/6J (Slc11 $\left.a^{\mathrm{s}}, \mathrm{H}-2^{\mathrm{b}}\right)$ mice (Charles River Japan, Yokohama, Japan) were injected intraperitoneally with cyclophosphamide at three days preinfection and on the day of infection at a dose of 200 $\mathrm{mg} / \mathrm{kg}$ [11]. C57BL/6 mice were more susceptible than BALB/c (Slc11a,$\left.H-2^{\mathrm{d}}\right)$ mice to Psedomonas aeruginosa infection in the agar-bead model [12]. The mice were intranasally inoculated with $20 \mu \mathrm{l}$ of the bacterial suspen- sion in BSG $\left(1 \times 10^{9} \mathrm{CFU} /\right.$ mouse $)$. Each mouse received intragastric administration of AMP, AZM, CLR, cefcapene pivoxil (CFPN-PI), or LVX (100 mg/kg/day) suspended in $0.5 \%$ (wt/vol) methylcellulose $(400 \mathrm{cP}$ ). All antibiotic treatments except AZM were administered using a stomach sonde attached to a 1-ml syringe three times daily, while AZM was administered once daily for three days after infection. Control mice received intragastric administration of $0.5 \%$ methylcellulose three times daily for three days after infection. On day 4 after infection, the lung was removed, homogenized with BSG, and plated in order to determine the number of CFU [10,13-15].

\section{Statistics}

Significant differences between the means plus or minus standard deviations (SDs) of different groups were examined using a two-tailed unpaired Student's $t$ test. A P value of $<0.05$ was regarded as statistically significant.

\section{Results \\ In vitro susceptibility testing}

The MICs of AMP, AZM, CLR, CFPN, LVX, and GEN against the six strains of NTHi are shown in Table 1 . The MIC ranges of the antibiotics tested against the three BLNAR and the three BLNAS strains were as follows: BLNAR, AMP 1-4 mg/l; AZM 0.25-8 mg/l; CLR $\geq 8 \mathrm{mg} / \mathrm{l}$; CFPN $1 \mathrm{mg} / \mathrm{l} ; \mathrm{LVX} \leq 0.125 \mathrm{mg} / \mathrm{l}$; and GEN $4 \mathrm{mg} / \mathrm{l} ; \mathrm{BLNAS}$, AMP 0.25-0.5 mg/l; AZM 4-8 mg/l; CLR 8-16 mg/l; CFPN 0.063-0.125 mg/l; LVX $\leq 0.125 \mathrm{mg} / \mathrm{l}$; and GEN 2$4 \mathrm{mg} / \mathrm{l}$. It was clearly shown that LVX has high in vitro potency against both the BLNAR and BLNAS strains. Both AMP and CFPN also showed high potency against the BLNAS strains.

\section{Extracellular potency of antibiotics against $\mathbf{H}$. influenzae entry into $A 549$ cells}

We first examined the entry level of NTHi strains into A549 cells using a GEN protection assay. Although there was somewhat less variability in invasiveness among strains, two (YS001 and YS005) of the six tested strains were considered to be invasive strains (Fig. 1). It was reported previously in TEM analyses and confocal macroscopic studies that NTHi can initiate cytoskeletal rear-

Table I: In vitro potency of six antimicrobial agents against six clinical isolates of NTHi.

\begin{tabular}{|c|c|c|c|c|c|c|c|}
\hline \multirow[t]{2}{*}{ strain } & \multicolumn{6}{|c|}{ MIC $(\mu g / m l)$} & \multirow[t]{2}{*}{ BLNAR or BLNAS } \\
\hline & AMP & AZM & CLR & CFPN & LVX & GEN & \\
\hline YSOOI & 4 & 8 & $>16$ & I & $\leq 0.125$ & 4 & BLNAR \\
\hline YSO02 & 4 & 0.25 & 8 & I & $\leq 0.125$ & 4 & BLNAR \\
\hline YSO05 & I & 8 & 16 & I & $\leq 0.125$ & 4 & BLNAR \\
\hline YS008 & 0.25 & 4 & 8 & 0.125 & $\leq 0.125$ & 4 & BLNAS \\
\hline YSO09 & 0.5 & 4 & 16 & 0.125 & $\leq 0.125$ & 2 & BLNAS \\
\hline YSOIO & 0.25 & 8 & 16 & 0.063 & $\leq 0.125$ & 4 & BLNAS \\
\hline
\end{tabular}




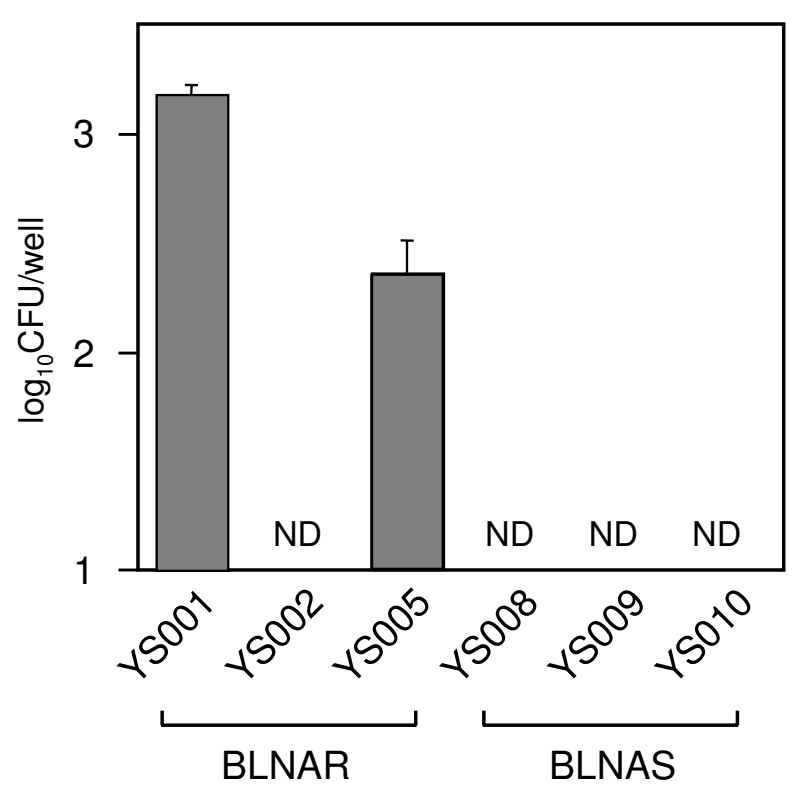

Figure I

Entry of $H$. influenzae into A549 cells. Cell cultures $\left(1 \times 10^{5}\right.$ cells/well) were infected for I h at $37^{\circ} \mathrm{C}$ with I $\times 10^{7} \mathrm{CFU}$ of YS00I, YS002, YS005, YS008, YS009, or YSOI0. At I h after infection, the cell culture medium was exchanged for fresh medium containing GEN (I00 $\mu \mathrm{g} / \mathrm{ml})$. One hour later, the surviving intracellular bacteria were enumerated by plating. Data represent the means \pm SD of three experiments with triplicate assays. ND, not detected.

rangement within the human airway epithelium, resulting in the internalization of the bacteria within nonciliated human airway epithelial cells by the process of macropinocytosis [16]. Using TEM analysis, we detected the microvilli of A549 cells surrounding organisms, as shown in Fig. 2. Therefore, we assume that some but not all NTHi strains are able to enter epithelial cells by the process of macropinocytosis. We next examined the inhibitory effects of each antibiotic on the entry and replication of YS001 and YS005 in A549 cells. The cells were infected with either YS001 or YS005 $(\mathrm{MOI}=100)$ for $1 \mathrm{~h}$ at $37^{\circ} \mathrm{C}$ in the cell culture medium supplemented with each antibiotic (AMP, AZM, CLR, CFPN, or LVX; $1 \mu \mathrm{g} / \mathrm{ml}$ ) or in cell culture medium that was not supplemented. Figure 3 shows that the LVX treatment was the most effective of the antibiotics tested in the present study in suppressing the entry of every strain into this line of cells. AMP or AZM treatment decreased the number of intracellular bacteria of each strain by $70-85 \%$, while CLR or CFPN treatment decreased the number of bacteria by $30-50 \%$. These results indicate that the ranking of the treatments in terms of their efficacy for suppressing the entry of invasive BLNAR strains was LVX $>$ AMP $=\mathrm{AZM}>\mathrm{CLR}=\mathrm{CFPN}$.
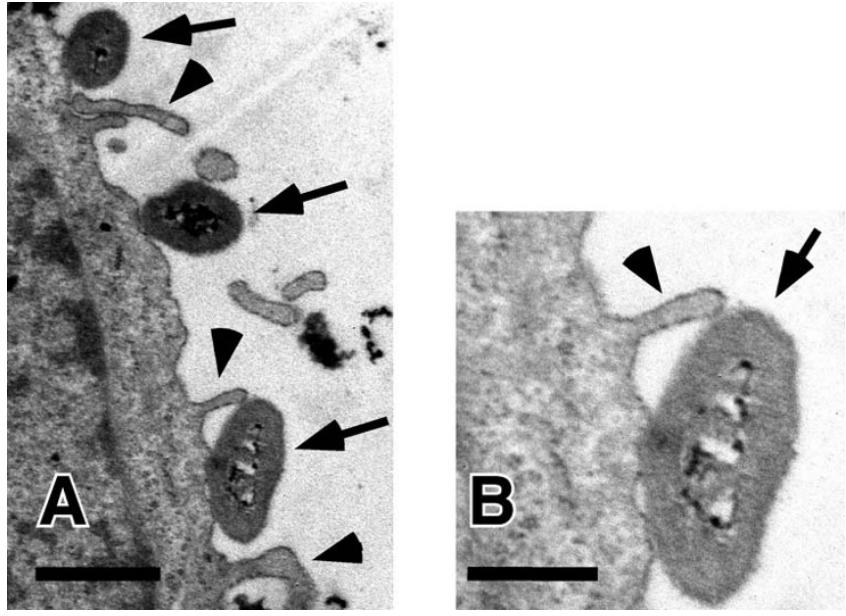

Figure 2

Electric microscopic observation of A549 cells infected with YSOOI. Bacteria attached (arrows) to the cell and the microvilli (arrow heads) of the cell are recognized. Bars, I $\mu \mathrm{m}(\mathrm{A})$ and $0.5 \mu \mathrm{m}(\mathrm{B})$.

\section{Intracellular potency of antibiotics against $\mathbf{H}$. influenzae within A549 cells}

After infection with YS001 or YS005 for $1 \mathrm{~h}$ at $37^{\circ} \mathrm{C}$ in the cell culture medium without supplementation of any antibiotic followed by subsequent incubation for $1 \mathrm{~h}$ in fresh medium supplemented with GEN to kill extracellular bacteria, the infected monolayers were further incubated with fresh culture medium supplemented with each antibiotic (AMP, AZM, CLR, CFPN, or LVX; $1 \mu \mathrm{g} / \mathrm{ml}$ ) or not supplemented for $2 \mathrm{~h}$ at $37^{\circ} \mathrm{C}$. Figure 4 shows that the LVX treatment was the most effective in reducing the number of intracellular bacteria of every strain. In contrast, intracellular bactericidal activities brought about by treatment with the other four antibiotics were detected in each strain, but to different degrees. The intracellular bactericidal activity against invasive BLNAR strains of the tested antibiotics can be ranked as follows: $\mathrm{LVX}>\mathrm{AZM}>\mathrm{AMP}=\mathrm{CLR}=\mathrm{CFPN}$.

\section{Mouse model of intranasal infection with $\mathbf{H}$. influenzae}

To date, mouse models of $H$. influenzae pneumonia have been rarely reported since it is difficult for this bacterium to infect mice $[17,18]$. Therefore, we pursued a new mouse model of NTHi lung infection in order to evaluate the efficacy of the antibiotics tested. In the present study, we used 4-week-old C57BL/6 mice. Generally, young immature mice are more susceptible to bacterial infection than fully grown mice [19]. In addition, the mice were pretreated intraperitoneally with cyclophosphamide to induce granulocytopenia [20]. We previously observed a decrease of at least $90 \%$ in peripheral blood granulocytes after cyclophosphamide treatment [11]. When cyclophos- 
A

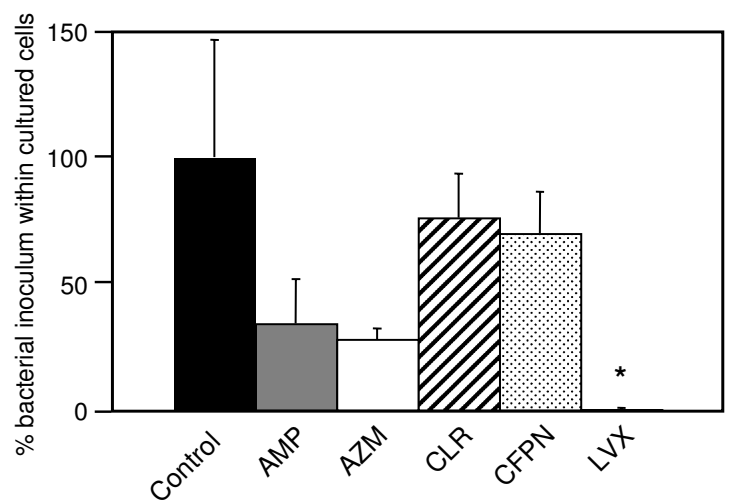

B

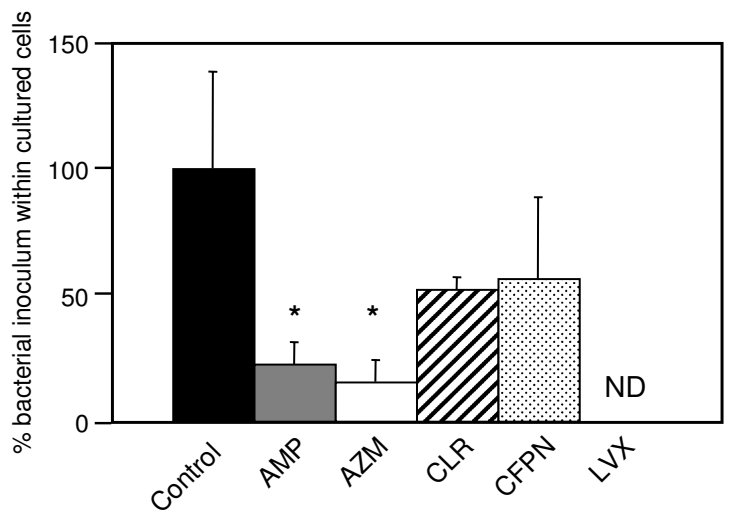

Figure 3

The invasion suppression assay of antibiotics. A549 cells ( $\mathrm{I} \times$ $10^{5}$ cells/well) were infected for $1 \mathrm{~h}$ at $37^{\circ} \mathrm{C}$ with $\mathrm{I} \times 10^{7}$ CFU of YSOOI (A) or YSO05 (B) in the presence or absence (control) of AMP, AZM, CLR, CFPN, or LVX (I $\mu \mathrm{g} / \mathrm{ml})$. At I $h$ after infection, the cell culture medium was exchanged for fresh medium containing GEN ( $100 \mu \mathrm{g} / \mathrm{ml})$. One hour later, surviving intracellular bacteria were enumerated by plating. Data represent the means \pm SD of three experiments with triplicate assays. $*, P<0.05$ (compared with control). ND, not detected.

phamide-pretreated mice were intranasally inoculated with $1 \times 10^{9} \mathrm{CFU}$ of $\mathrm{NTHi}$, the bacteria continuously resided in the lungs of the mice at more than $10^{5} \mathrm{CFU}$ when monitored for up to four days after inoculation (data not shown).

\section{Efficacies of antibiotics against $\mathrm{H}$. influenzae colonization in mouse lung}

We evaluated the efficacy of the antibiotics for reducing the colonization of NTHi in the mouse lung. Based on the data from previous reports [21-24] and the suppliers' instructions, we estimated peak antibiotic concentrations of 1 to $2 \mu \mathrm{g} / \mathrm{ml}$ (AZM and CFPN-PI), 2 to $3 \mu \mathrm{g} / \mathrm{ml}$ (AMP and LVX), or 5 to $6 \mu \mathrm{g} / \mathrm{ml}$ (CLR) in the blood of mice from 30 to $120 \mathrm{~min}$ after intragastric administration. Figure 5
A

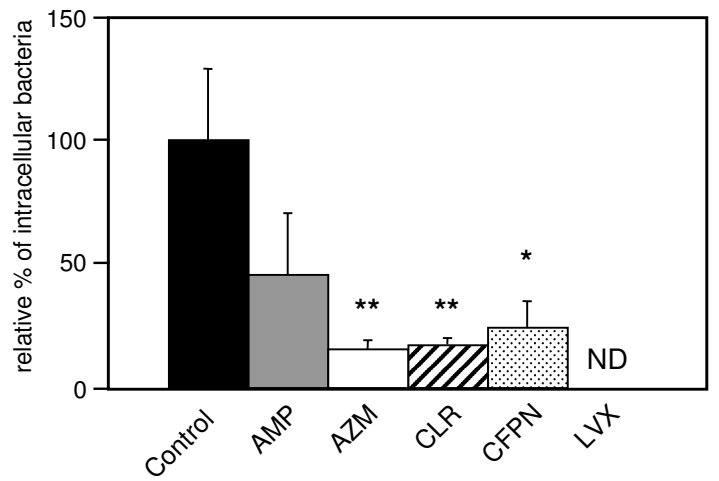

B

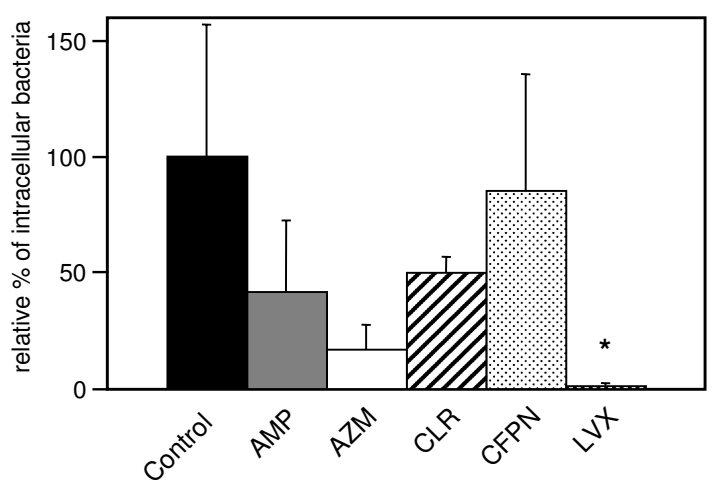

Figure 4

Intracellular killing assay of antibiotics. A549 cells $\left(\mathrm{I} \times 10^{5}\right.$ cells/well) were infected for I h at $37^{\circ} \mathrm{C}$ with I $\times 10^{7} \mathrm{CFU}$ of YSOOI (A) or YSO05 (B) in the absence of antibiotics. After a I-h infection followed by a I-h incubation period with GEN $(100 \mu \mathrm{g} / \mathrm{ml})$, the cell culture was incubated in the presence or absence (control) of AMP, AZM, CLR, CFPN, or LVX (I $\mu \mathrm{g} /$ $\mathrm{ml})$. Two hours later, the surviving intracellular bacteria were enumerated by plating. Data represent the means $\pm S D$ of three experiments with triplicate assays. *, $P<0.05$ (compared with control). **, $P<0.01$ (compared with control). ND, not detected.

shows that the intragastric administration of LVX was extremely effective against both the BLNAR and BLNAS strains of NTHi. The AZM treatment was also extremely effective for the complete eradication of BLNAS strains from the lung, while the CLR treatment showed no efficacy. Treatment with AMP or CFPN-PI was also highly effective against BLNAS infection. However, except for LVX, none of the tested antibiotics was found to be effective against invasive BLNAR strains.

\section{Discussion}

NTHi strains are not traditionally considered to be invasive $[1,25]$; however, recent works have shown that NTHi can penetrate human respiratory epithelial cell lines $[4,7]$ and primary human airway epithelial cells [16]. In addi- 
A
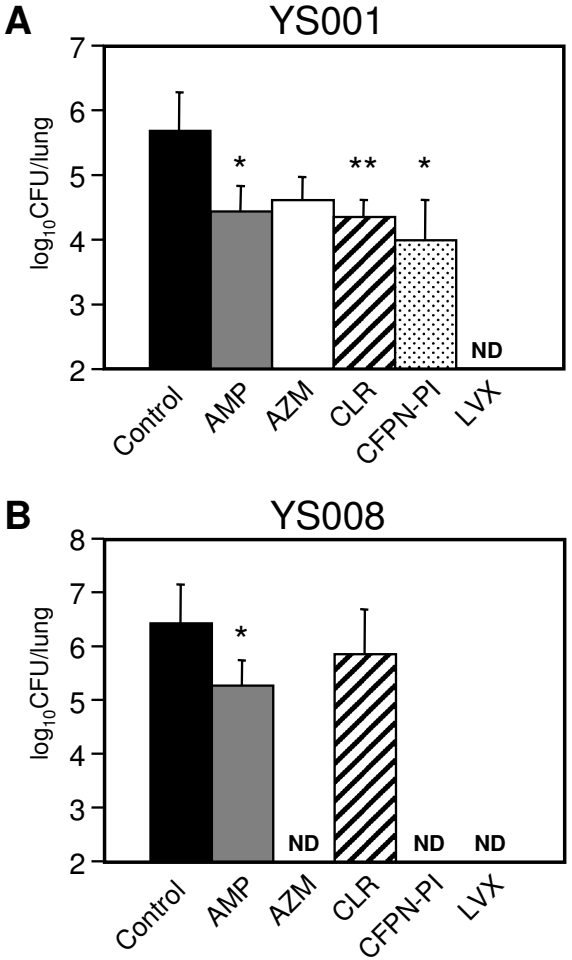
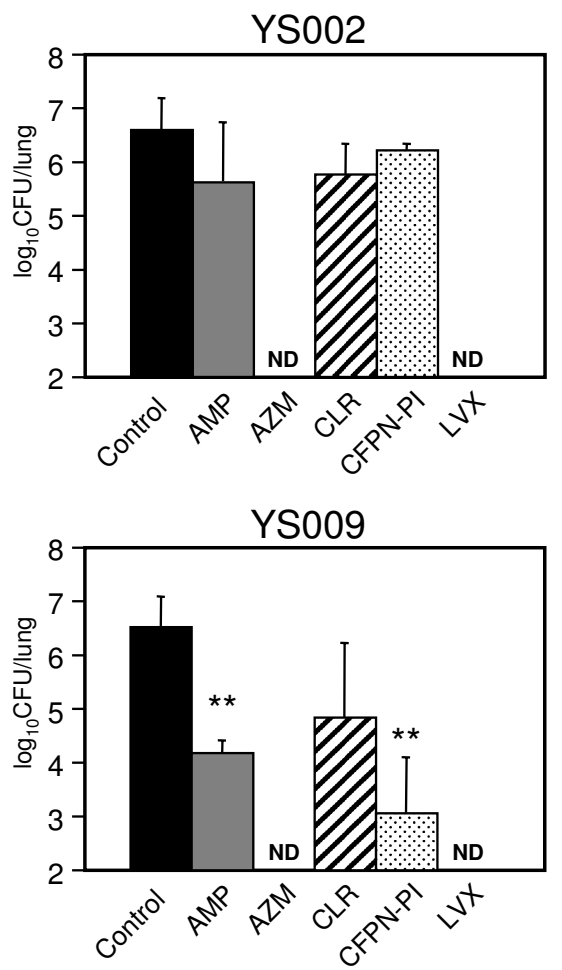
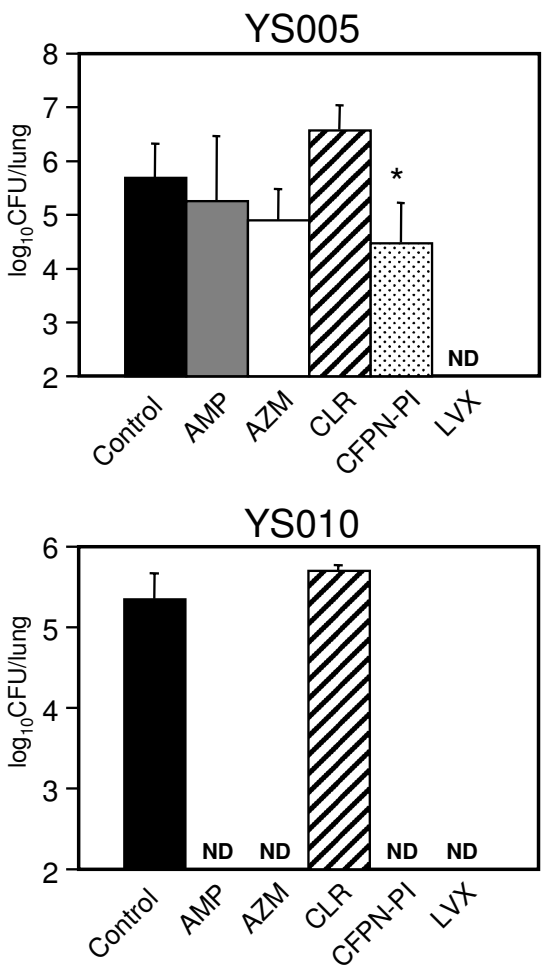

Figure 5

Bacterial clearance by antibiotic treatment in the lung. Mice infected intranasally with YS00I, YS002, YS005, YS008, YS009, or YSOIO were intragastically administered AMP, AZM, CLR, CFPN-PI, LVX (I00 mg/kg/day), or methylcellulose (control) once (AZM) or three times (AMP, CLR, CFPN-PI, LVX, and methylcellulose) daily for three days after infection. On day 4 after infection, the mice were harvested, and bacterial loads were determined in lung homogenates. Data represent the means \pm SD of five mice per group. *, $P<0.05$ (compared with control). **, $P<0.01$ (compared with control). ND, not detected.

tion, some reports have shown that NTHi can reside intracellularly in human tissue samples $[3,9,26]$. In the present study, two of the three BLNAR strains examined certainly entered the A549 human lung epithelial cell line (Fig. 1). Nevertheless, in the mouse infection model, there were no differences in the infection doses of bacteria in the lung homogenates between BLNAR and BLNAS or between invasive and noninvasive strains (Fig. 5). To date, we have been unable to detect intracellular bacteria in lung sections by TEM analysis after infection with NTHi.

LVX showed potent in vitro antibacterial activity against both the BLNAR and BLNAS strains (Table 1), and was found to be overwhelmingly effective against invasive BLNAR strains in the cell culture infection model (Figs. 3 and 4). After 1-h incubation in $5 \% \mathrm{CO}_{2}$ at $37^{\circ} \mathrm{C}$, LVX used at a concentration of $1 \mu \mathrm{g} / \mathrm{ml}$ ( $\geq 8$ times the MIC) killed about $99 \%$ of bacteria (both YS001 and YS005) in the cell culture medium; still, as many as $1 \times 10^{5} \mathrm{CFU}$ per well of extracellular bacteria were present after the LVX treatment (data not shown). The $1 \times 10^{5} \mathrm{CFU}$ of live bacteria was surplus to the amount required for entering the cells, since YS001 and YS005 were able to enter the cells with $1.3 \times$ $10^{3} \mathrm{CFU}$ and $2.4 \times 10^{2} \mathrm{CFU}$, respectively (Fig. 2). Consequently, LVX appears to have an extracellular potency to suppress the invasion of bacteria, since almost no bacterium was detected within the cells after the LVX treatment (Fig. 3). By comparison, it seems that AMP, AZM, or CLR used at lower concentrations of $1 / 4,1 / 8$, or $1 / 16$ of $\mathrm{MIC}$, respectively, all have extracellular potency to suppress the invasion of BLNAR strains into A549 cells, as shown in Fig. 3. We have previously reported that a sub-MIC of AZM can reduce the invasive activity of Salmonella enterica serovar Typhimurium into the Henle-407 human intestinal epithelial cell line [10]. Presumably, then, a sub-MIC of each antibiotic might affect the expression of the bacterial invasion apparatus directly and/or indirectly. Fluoroquinolones have long been known to accumulate in eukaryotic cells. The cellular concentrations of fluoroquinolones are generally 4 - to 10 -fold higher than the extracellular concentrations [27]. In contrast, up to now, all studies have reported a lack of accumulation (i.e., an 
apparent intracellular concentration lower than the extracellular concentration at equilibrium) for all $\beta$-lactams [27].

In sharp contrast with $\beta$-lactams, macrolides show a marked intracellular accumulation in almost all cells. The cellular concentrations of CLR and AZM are 10- to 20-fold and 40- to 300-fold larger, respectively, than the extracellular concentrations [27]. Still, it seems that every antibiotic can reduce the intracellular CFU of invasive BLNAR strains to some extent, as shown in Fig. 4. Accordingly, intracellular bacteria are exposed to various killing actions of the cells. Most obligate and facultative intracellular bacteria have mechanisms for escaping from the killing systems inside the cells. In contrast to such bacteria, the response of NTHi to the defense system inside the cells remains unclear; however, intracellular NTHi must suffer a synergy effect between the activity of the antibiotic and the killing actions of the cells. Moreover, we must also consider the fact that antibiotics may exert either favorable or unfavorable action on the host cells, which in turn modulate the bactericidal activity of the antibiotics [27].

H. influenzae is a strict parasite of humans which efficiently colonizes the upper respiratory tract [1]. When constructing the mouse model of intranasal infection with NTHi, we considered using the ICR, ddY, and C57BL/6 mouse strains. As a result of the preliminary experiments, intranasally inoculated bacteria were detected in the lungs of cyclophosphamide-pretreated $\mathrm{C} 57 \mathrm{BL} / 6$ mice, while the inoculated bacteria were not detected in the lungs of cyclophosphamide-pretreated ICR or ddY mice. On the one hand, C57BL/6 mice carry the Nramp1D169 (natural resistance-associated macrophage protein 1 gene; new nomenclature, Slc11a1) allele (a point mutation at nucleotide position 596, resulting in a glycine-to-aspartate substitution) in the genetic background. On the other hand, ICR and ddY mice carry the Nramp1G169 gene. A single locus (Nramp1) that is mapped to the proximal region of mouse chromosome 1 has been shown to influence the early phase of bacterial replication in reticuloendothelial cells [28]. The expression of Nramp1 in mice confers innate resistance to certain bacterial infections such as Mycobacterium bovis (BCG), Leishmania donovani, and S. enterica serovar Typhimurium [29,30]. Therefore, C57BL/ 6 mice are susceptible to infection with these bacteria. It is possible that the expression of Nramp1 in mice would also confer innate immunity to infection with $H$. influenzae, so NTHi could colonize in the lungs of C57BL/6 mice after intranasal infection.

It has been reported that in Japanese and U.S. clinical isolates, the prevalence rates of each resistance class of $H$. influenzae in Japan $(\mathrm{n}=296)$ and the United States $(\mathrm{n}=$ 100 ) are, respectively, $55.1 \%$ and $46 \%$ for BLNAS; $26.4 \%$ and $13 \%$ for low-BLNAR with a low degree of AMP resistance; $13.2 \%$ and $0 \%$ for BLNAR; $3 \%$ and $36 \%$ for TEM- 1 type and ROB-1 type $\beta$-lactamase-producing AMP-resistant $H$. influenzae (BLPAR); and $2.4 \%$ and $3 \%$ for $\mathrm{Hib}$ strains [31]. These data indicate a worldwide increase of AMP-resistant $H$. influenzae isolates. Therefore, it seems likely that the use of fluoroquinolones or macrolides for the oral treatment of respiratory tract infections associated with $H$. influenzae should be useful. In fact, fluoroquinolones have been widely used in the treatment of respiratory tract infections, and their use has increased extensively in hospitals and long-term care facilities [32]. However, it has also been reported that the emergence of $H$. influenzae isolates with reduced susceptibility to fluoroquinolones is becoming a clinical and public health concern [33-35]. Under these circumstances, the new guidelines in the context of the risk management of community-acquired pneumonia in adults are the following: Young and otherwise healthy patients who can be safely treated as outpatients will usually respond to AZM. Doxycycline should be used with caution because of increasing resistance to this agent, and reserved for use when other options are not available. Older patients, or those with substantial comorbidities, will usually respond well to combinations of a $\beta$-lactam agent (such as high-dose amoxicillin/clavulanate) plus a macrolide. Newer generation recommended (so-called "respiratory") fluoroquinolones can be used as first-line agents but should be reserved for use in higher risk or drug-intolerant patients in order to slow the emergence of resistance to this class of drugs [36]. Therefore, in spite of the fact that the oral LVX treatment showed excellent therapeutic efficacy in the mouse model of intranasal infection with NTHi compared with other antibiotic treatments (Fig. 5), fluoroquinolones should be avoided or used with great caution. As another option, combinations of a $\beta$-lactam agent plus a macrolide could be expected to have a modest therapeutic benefit in the oral treatment of respiratory tract infections associated with $H$. influenzae, which we will examine in future studies.

Miyazaki et al. have demonstrated that although the MICs of AZM and CLR are similar for three strains of $H$. influenzae (BLNAR, BLNAS, and BLPAR) at a dose of $50 \mathrm{mg} / \mathrm{kg}$, the area under the concentration curve and the half-life of AZM in the lungs are 3-fold higher and 6-fold longer, respectively, than those of CLR in mice. Thus, the authors concluded that AZM may be useful for both AMP-susceptible and AMP-resistant bronchopneumonia caused by $H$. influenzae infections [5]. The present results support their conclusion. AZM has potent antibacterial activity against BLNAS strains in mice compared with CLR (Fig. 5). It is well known that since AZM, the only azalide macrolide antibiotic, has the advantage of an extensive half-life of approximately $68 \mathrm{~h}$, it is possible to administer it once a 
day for a short duration while sustaining effective serum and tissue concentrations for at least 10 days [37]. The intracellular (i.e., within leukocytes and fibroblasts) and tissue concentrations of AZM make it an excellent option for intracellular pathogens [37]. The dose and frequency of the oral administration of each antibiotic used in the present study in the treatment of a $70 \mathrm{~kg}$ adult human as recommended by the suppliers are as follows: AMP, 250$500 \mathrm{mg}$, four to six times daily; AZM, $500 \mathrm{mg}$ once daily; CLR, $200 \mathrm{mg}$, twice daily; CFPN-PI, $100 \mathrm{mg}$, three times daily; and LVX, $100 \mathrm{mg}$, three times daily. Therefore, the dose for the oral administration of each antibiotic in mice in the present study was set at $100 \mathrm{mg} / \mathrm{kg}$ daily, which is thought to be two to 23 times more than sufficient to produce effective antibacterial activity. Nevertheless, with the exception of LVX, we found no antibiotics that were effective against invasive BLNAR strains (YS001 and YS005) in the mouse infection model (Fig. 5). We hope that our future studies on invasive BLNAR strains using the mouse infection model will identify effective antibiotics for human medical use.

\section{Conclusion}

In summary, fluoroquinolone LVX had potent activities against both the process of invasion into the A549 human lung epithelial cell line and the residence in the cell line of invasive BLNAR strains of NTHi, as compared with AMP, AZM, CLR, and CFPN. For the mouse model of infection with NTHi, four-week-old female C57BL/ 6 mice were pretreated intraperitoneally with cyclophosphamide to induce granulocytopenia before intranasal infection with NTHi. We evaluated the efficacy of the antibiotics at reducing the colonization of NTHi in the mouse lung. The results showed that LVX was extremely effective in treating both the BLNAR and BLNAS strains of NTHi as compared with AMP, AZM, CLR, and CFPN-PI. In particular, with the exception of LVX, there were no antibiotics that were effective against invasive BLNAR strains in the mouse infection model. These observations provide evidence that fluoroquinolones have great bactericidal activities against quinolone-susceptible NTHi strains. Further studies are needed to identify effective antibiotics for human use other than fluoroquinolones as an initial treatment that provides coverage of both BLNAR and BLNAS or invasive and noninvasive strains of NTHi.

\section{Abbreviations}

AMP: Ampicillin; AZM: Azithromycin; BLNAR: $\beta$-lactamase-negative AMP-resistant Haemophilus influenzae; BLNAS: $\beta$-lactamase-negative AMP-susceptible Haemophilus influenzae; BLPAR: $\beta$-lactamase-producing AMPresistant Haemophilus influenzae; BSG: Phosphate-buffered saline containing $0.01 \%(\mathrm{wt} / \mathrm{vol}$ ) gelatin, $\mathrm{pH} 7.4$; NTHi: Nonencapsulated and nontypeable Haemophilus influenzae; CFPN: Cefcapene; CFPN-PI: CFPN pivoxil; CFU: Col- ony-forming units; CLR: Clarithromycin; DMEM: Dulbecco's modified Eagle's medium; GEN: Gentamicin; HBSS: Hanks' balanced salt solution; LVX: Levofloxacin; MIC: Minimum inhibitory concentration; MOI: Multiplicity of infection; NAD: Nicotinamide adenine dinucleotide; PBS: Phosphate-buffered saline, pH7.4; SD: Standard deviation; TEM: Transmission electron microscope.

\section{Competing interests}

The author(s) declare that they have no competing interests.

\section{Authors' contributions}

YS and HM carried out most of the experiments; ME helped with the cell culture model of the infection experiments; MN helped with the TEM analysis; KU supplied the NTHi strains and provided advice on the experiments and manuscript; SO provided advice on the experiments and manuscript; HM designed all the experiments and prepared the manuscript.

\section{Acknowledgements}

To Dr. Shuichi Miyazaki of Toho University for his technical advice. To Mr. Chihiro Aikawa and Mr. Takeaki Wajima for their technical assistance. To Pfizer Pharmaceuticals, Inc., for research grant support.

\section{References}

I. Tang CM, Hood DW, Moxon ER: Pathogenesis of Haemophilus influenzae infections. In Principles of Bacterial Pathogenesis Edited by: Groisman EA. San Diego: Academic Press; 200I:675-716.

2. Johnson PD, Oppedisano F, Bennett-Wood V, Gilbert GL, RobinsBrowne RM: Sporadic invasion of cultured epithelial cells by Haemophilus influenzae type b. Infect Immun 1996, 64: I05 I-I053.

3. O'Neill JM, St Geme JW 3rd, Cutter D, Adderson EE, Anyanwu J, Jacobs RF, Schutze GE: Invasive disease due to nontypeable Haemophilus influenzae among children in Arkansas. J Clin Microb 2003, 4 I:3064-3069.

4. van Schilfgaarde M, van Alphen L, Eijk P, Everts V, Dankert J: Paracytosis of Haemophilus influenzae through cell layers of $\mathrm{NCl}$ H292 lung epithelial cells. Infect Immun 1995, 63:4729-4737.

5. Miyazaki S, Fujikawa T, Matsumoto T, Tateda K, Yamaguchi K: Efficacy of azithromycin, clarithromycin and beta-lactam agents against experimentally induced bronchopneumonia caused by Haemophilus influenzae in mice. J Antimicrob Chemother 200I, 48:425-430.

6. Ubukata K, Chiba N, Hasegawa K, Shibasaki Y, Sunakawa K, Nonoyama M, Iwata S, Konno M: Differentiation of beta-lactamasenegative ampicillin-resistant Haemophilus influenzae from other $\boldsymbol{H}$. influenzae strains by a disc method. J Infect Chemother 2002, 8:50-58.

7. St Geme JW 3rd, Falkow S: Haemophilus influenzae adheres to and enters cultured human epithelial cells. Infect Immun I990, 58:4036-4044.

8. St Geme JW 3rd, Falkow S: Loss of capsule expression by Haemophilus influenzae type $b$ results in enhanced adherence to and invasion of human cells. Infect Immun I99I, 59:I325-I333.

9. Forsgren J, Samuelson A, Ahlin A, Jonasson J, Rynnel-Dagoo B, Lindberg A: Haemophilus influenzae resides and multiplies intracellularly in human adenoid tissue as demonstrated by in situ hybridization and bacterial viability assay. Infect Immun I994, 62:673-679.

10. Matsui H, Eguchi M, Ohsumi K, Nakamura A, Isshiki Y, Sekiya K, Kikuchi Y, Nagamitsu T, Masuma R, Sunazuka T, Omura S: Azithromycin inhibits the formation of flagellar filaments without 
suppressing flagellin synthesis in Salmonella enterica serovar Typhimurium. Antimicrob Agents Chemother 2005, 49:3396-3403.

II. Gulig PA, Doyle T], Hughes JA, Matsui H: Analysis of host cells associated with the Spv-mediated increased intracellular growth rate of Salmonella typhimurium in mice. Infect Immun 1998, 66:247|-2485.

12. Tam M, Snipes G], Stevenson MM: Characterization of chronic bronchopulmonary Pseudomonas aeruginosa infection in resistant and susceptible inbred mouse strains. Am J Respir Cell Mol Biol 1999, 20:710-7I9.

13. Kodama C, Eguchi M, Sekiya Y, Yamamoto T, Kikuchi Y, Matsui H: Evaluation of the Lon-deficient Salmonella strain as an oral vaccine candidate. Microbiol Immunol 2005, 49: I035-I045.

14. Matsui H, Suzuki M, Isshiki Y, Kodama C, Eguchi M, Kikuchi Y, Motokawa K, Takaya A, Tomoyasu T, Yamamoto T: Oral immunization with ATP-dependent protease-deficient mutants protects mice against subsequent oral challenge with virulent Salmonella enterica serovar Typhimurium. Infect Immun 2003, 7I:30-39.

15. Kodama C, Matsui H: Salmonella flagellin is not a dominant protective antigen in oral immunization with attenuated live vaccine strains. Infect Immun 2004, 72:2449-245I.

16. Ketterer MR, Shao JQ, Hornick DB, Buscher B, Bandi VK, Apicella $M A:$ Infection of primary human bronchial epithelial cells by Haemophilus influenzae : macropinocytosis as a mechanism of airway epithelial cell entry. Infect Immun 1999, 67:416I-4I70.

17. Miyazaki S, Nunoya T, Matsumoto T, Tateda K, Yamaguchi K: New murine model of bronchopneumonia due to cell-bound Haemophilus influenzae. J Infect Dis 1997, I75:205-209.

18. Vallee E, Azoulay-Dupuis E, Pocidalo JJ, Bergogne-Berezin E: Activity and local delivery of azithromycin in a mouse model of Haemophilus influenzae lung infection. Antimicrob Agents Chemother 1992, 36:1412-1417.

19. Burns-Guydish SM, Olomu IN, Zhao H, Wong RJ, Stevenson DK, Contag $\mathrm{CH}$ : Monitoring age-related susceptibility of young mice to oral Salmonella enterica serovar Typhimurium infection using an in vivo murine model. Ped Res 2005, 58: I53- 158.

20. McIntyre KW, Unowsky J, DeLorenzo W, Benjamin W: Enhancement of antibacterial resistance of neutropenic, bone marrow-suppressed mice by interleukin-I alpha. Infect Immun 1989, 57:48-54.

21. Girard AE, Girard D, English AR, Gootz TD, Cimochowski CR, Faiella JA, Haskell SL, Retsema JA: Pharmacokinetic and in vivo studies with azithromycin (CP-62,993), a new macrolide with an extended half-life and excellent tissue distribution. Antimicrob Agents Chemother 1987, 3 I:1948-1954.

22. Guinea J, Robert M, Gargallo-Viola D, Xicota MA, Garcia J, Tudela E, Esteve $M$, Coll $R$, Pares $M$, Roser $R$ : In vitro and in vivo antibacterial activities of E-4868, a new fluoroquinolone with a 7 azetidin ring substituent. Antimicrob Agents Chemother 1993, 37:868-874.

23. Comber KR, Osborne CD, Sutherland R: Comparative effects of amoxycillin and ampicillin in the treatment of experimental mouse infections. Antimicrob Agents Chemother 1975, 7:179-185.

24. Tessier PR, Kim MK, Zhou W, Xuan D, Li C, Ye M, Nightingale CH, Nicolau DP: Pharmacodynamic assessment of clarithromycin in a murine model of pneumococcal pneumonia. Antimicrob Agents Chemother 2002, 46:1425-1434.

25. Foxwell AR, Kyd JM, Cripps AW: Nontypeable Haemophilus influenzae: pathogenesis and prevention. Microb Mol Biol Rev 1998, 62:294-308

26. Bandi V, Apicella MA, Mason E, Murphy TF, Siddiqi A, Atmar RL, Greenberg SB: Nontypeable Haemophilus influenzae in the lower respiratory tract of patients with chronic bronchitis. Am J Respir Crit Care Med 200I, 164:2II4-2II9.

27. Carryn S, Chanteux H, Seral C, Mingeot-Leclercq MP, Van Bambeke F, Tulkens PM: Intracellular pharmacodynamics of antibiotics. Infect Dis Clin North Am 2003, 17:615-634.

28. Wyllie S, Seu P, Goss JA: The natural resistance-associated macrophage protein I Slcl Ial (formerly NrampI) and iron metabolism in macrophages. Microbes Infect 2002, 4:35I-359.

29. Vidal S, Tremblay ML, Govoni G, Gauthier S, Sebastiani G, Malo D Skamene E, Olivier M, Jothy S, Gros P: The Ity/Lsh/Bcg locus: natural resistance to infection with intracellular parasites is abrogated by disruption of the Nrampl gene. J Exp Med 1995 , 182:655-666.
30. Vidal SM, Malo D, Vogan K, Skamene E, Gros P: Natural resistance to infection with intracellular parasites: isolation of a candidate for Bcg. Cell 1993, 73:469-485.

31. Hasegawa K, Yamamoto K, Chiba N, Kobayashi R, Nagai K, Jacobs MR, Appelbaum PC, Sunakawa K, Ubukata K: Diversity of ampicillin-resistance genes in Haemophilus influenzae in Japan and the United States. Microb Drug Resist 9:39-46.

32. Cazzola M, Donner CF: The need for a new fluoroquinolone. Pulm Pharmacol Therapeut 2006, I9(Suppl I): I-3.

33. Nazir J, Urban C, Mariano N, Burns J, Tommasulo B, Rosenberg C, Segal-Maurer S, Rahal JJ: Quinolone-resistant Haemophilus influenzae in a long-term care facility: clinical and molecular epidemiology. Clin Infect Dis 2004, 38: I564-1569.

34. Vila J, Ruiz J, Sanchez F, Navarro F, Mirelis B, de Anta MT, Prats G: Increase in quinolone resistance in a Haemophilus influenzae strain isolated from a patient with recurrent respiratory infections treated with ofloxacin. Antimicrob Agents Chemother 1999, 43:16I-162.

35. Ho PL, Chow KH, Mak GC, Tsang KW, Lau YL, Ho AY, Lai EL, Chiu SS: Decreased levofloxacin susceptibility in Haemophilus influenzae in children, Hong Kong. Emerg Infect Dis 2004, 10:1960-1962.

36. Community-acquired pneumonia in adults [http://www.guide line.gov]

37. Duran JM, Amsden GW: Azithromycin: indications for the future? Expert Opin Pharmacother 2000, I:489-505.

\section{Pre-publication history}

The pre-publication history for this paper can be accessed here:

http://www.biomedcentral.com/1471-2334/8/15/prepub

Publish with Biomed Central and every scientist can read your work free of charge

"BioMed Central will be the most significant development for disseminating the results of biomedical research in our lifetime. "

Sir Paul Nurse, Cancer Research UK

Your research papers will be:

- available free of charge to the entire biomedical community

- peer reviewed and published immediately upon acceptance

- cited in PubMed and archived on PubMed Central

- yours - you keep the copyright 